\title{
PHONOLOGICAL VARIATION: EPENTHESIS AND DELETION OF SCHWA IN DUTCH
}

\author{
Cecile Kuijpers, Wilma van Donselaar \& Anne Cutler \\ Max-Planck-Institut für Psycholinguistik, Wundtlaan 1, 6525 XD \\ Nijmegen, The Netherlands, E-mail: cecile.kuijpers@mpi.nl
}

\begin{abstract}
Two types of phonological variation in Dutch, resulting from optional rules, are schwa epenthesis and schwa deletion. In a lexical decision experiment it was investigated whether the phonological variants were processed similarly to the standard forms. It was found that the two types of variation patterned differently. Words with schwa epenthesis were processed faster and more accurately than the standard forms, whereas words with schwa deletion led to less fast and less accurate responses. The results are discussed in relation to the role of consonant-vowel alternations in speech processing and the perceptual integrity of onset clusters.
\end{abstract}

\section{INTRODUCTION}

In Dutch, many phonological rules at the word level have an obligatory character, for instance Final Devoicing and Degemination (Booij, 1995). The final devoicing rule indicates that a voiced obstruent in word-final position becomes devoiced, e.g., 'rood' (red) is pronounced as [ro:t]. Degemination is obligatory as soon as a cluster of two identical consonants arises in a word, e.g., 'grootte' (size) is pronounced as [xro:tə]. However, not all phonological rules that apply within words are obligatory. There are also rules that optionally apply, such as Schwa Epenthesis and Schwa Deletion (see also Booij, 1995).

Schwa epenthesis typically occurs in non-homorganic consonant clusters consisting of liquids followed by noncoronals. In non-homorganic consonant clusters the constituent phonemes are realized at different places of articulation. For instance, the Dutch word 'tolk' [tolk] (interpreter) is also realized as 'tolluk' [tolək], and the word 'kerk' [kerk] (church) is also realized as [kerək]. Epenthetic schwa does not occur in clusters consisting of liquids and coronals, nor in clusters consisting of a nasal and a homorganic consonant (e.g. 'hals' [hals] (neck) can not be realized as *[haləs], and 'damp' [damp] (vapour) can not be realized as *[daməp]).
Schwa deletion occurs during the realization of polysyllabic, mostly trisyllabic words. Schwa is optionally deleted if the following syllable is headed by a full vowel, and especially if the preceding vowel is somewhat reduced. Words like 'envelop' [Envəlop] (envelop) and 'kapelaan' (curate) [kapəlan] are thus realized as [عnvlop] and [kaplan]. Schwa deletion is most likely to occur if the resulting cluster is an obstruent-liquid cluster, generally the most favoured kind of onset cluster (Booij, 1995).

In a phonological analysis schwa epenthesis is normally characterized as syllable-based. As indicated above, epenthetic schwa only occurs if the liquid-obstruent cluster is tautosyllabic and if the two segments do not share their place features (see Kager \& Zonneveld, 1986; Trommelen \& Zonneveld, 1989). However, epenthetic schwa also occurs in disyllabic words but only if the second syllable contains a schwa (e.g., 'erker' (bay) is realized as [عrkər] but also as [عrəkər]). Schwa epenthesis in disyllabic words is either explained by ambisyllabicity or by appendix theory. If the $/ \mathrm{k} /$ in 'erker' is considered ambisyllabic it is not only the onset in /kər/ but also part of the coda in /عrk/. Thus, the cluster /rk/ is syllable-final and epenthesis can occur (Berendsen \& Zonneveld, 1985). If the following segments /ər/ are treated as an appendix the cluster /rk/ is also considered syllable-final (see also de Haas, 1986; Trommelen \& Zonneveld, 1989).

From a phonetic point of view it is quite natural that only heterorganic consonant clusters are broken up since they require more articulatory effort than homorganic clusters (Booij, 1995). The articulators have to move from one place to the other, e.g., in 'tolk' [tolk] from alveolar /1/ to velar $/ \mathrm{k} /$. If the alveolar is pronounced with a backward tongue movement epenthetic schwa is not likely to appear, whereas an anterior articulation of the alveolar /1/ easily leads to schwa-insertion. In words like 'pols' [pols] (wrist) the place of articulation of the cluster /ls/ is alveolar and schwa epenthesis is prohibited.

So far, schwa epenthesis and schwa deletion in Dutch have mainly been described in phonological studies. In the 
present study psycholinguistic methods are used to ask how listeners process word forms with epenthesis and deletion. The realizations that diverge least from the orthographic forms are here considered the 'standard' forms ([tolk] and [kapəlan]); the realizations with schwa epenthesis and schwa deletion ([tolək] and [kaplan]) are considered the phonological variants.

Phonological variation in speech has been a topic of research in several studies. For instance, Gaskell \& Marslen-Wilson (1996) investigated the effects of contextually induced phonological assimilation on word recognition. Schwa epenthesis and schwa deletion cause the same lexical item to be realized in two different, acceptable ways. The aim of the present study is to investigate, in an auditory lexical decision experiment, whether listeners process the phonological variants as efficiently as the standard realizations. Since the phonological variants are optional it is predicted that the standard realizations would be responded most rapidly and most accurately.

\section{METHOD}

\subsection{Material}

Test items. Twelve items with schwa epenthesis (type 'tolk'), and 8 items with schwa deletion (type 'kapelaan') were selected from the CELEX database (Burnage, 1990). The items are indicated in Table 1. If schwa deletion takes place obstruent-liquid sequences are created that constitute legal onset clusters.

Filler items. One part of the filler material was matched to the test items and therefore occurred in two forms, i.e. with and without schwa. These were twelve monosyllabic and twelve disyllabic items with non-homorganic clusters (*golk/*golluk and *bilk/billuk), twelve monosyllabic items with homorganic clusters (vers/*verrus), and eight trisyllabic items with medial obstruent-liquid cluster (*kiepeloon/ *kieploon). The items indicated by an asterisk are all pseudowords. The additional filler material consisted of monosyllabic items, disyllabic items with full vowel and schwa, disyllabic items with two full vowels, and trisyllabic items. Fifty percent of the items were real words and fifty percent were pseudowords.

Recording. All items were read by a female speaker and recorded on DAT tape (Sony DAT recorder). The words were digitized with $20 \mathrm{kHz}$ sampling frequency and spliced using the speech editing system Xwaves.

\begin{tabular}{|c|c|}
\hline $\begin{array}{c}\text { phonological variation: } \\
\text { Epenthesis }\end{array}$ & $\begin{array}{c}\text { phonological variation: } \\
\text { Deletion }\end{array}$ \\
\hline 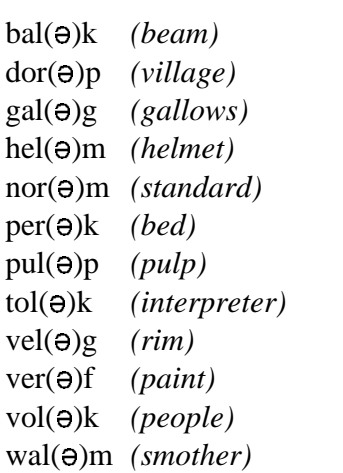 & 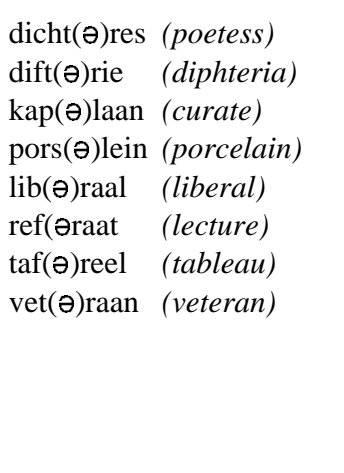 \\
\hline
\end{tabular}

Table 1: Stimulus words used in the lexical decision experiment. The inserted/deleted schwa is indicated between brackets.

\subsection{Subjects}

Fifty-six subjects, all students at the University of Nijmegen, were tested. They were all native speakers of Dutch and were paid for their participation.

\subsection{Procedure}

Two different realizations of each word, e.g., [tolk] vs. [tolək] and [kapəlan] vs. [kaplan], were tested. To avoid an effect of repetition of the same items two experimental versions were used. In both versions the same items occurred in the same order. Standard realizations and phonological variants were counterbalanced across the two versions. Subjects were tested in pairs, in separate soundtreated booths. All items were presented via headphones. Subjects had to decide as quickly as possible whether the stimulus was a real word or not. They made 'yes/no' responses to the stimuli by pressing the corresponding button. If subjects did not respond within $1500 \mathrm{~ms}$ the response was 'missing'. Reaction times were measured from word onset.

\section{RESULTS}

The average hit rate for the 'tolk' type of words was high, both for the standard forms and the realizations with epenthetic schwa. With respect to the 'kapelaan' type of words there was a large difference between the standard forms and the realizations with schwa deletion. Hit rates for both types of words are indicated in Figure 1. The 
light bars reflect the standard forms, the dark bars reflect the phonological variants. With respect to schwa epenthesis there was no significant difference between the hit rates for the standard forms and the words with schwa epenthesis. Realizations with schwa deletion had a lower hit rate than the standard forms. The difference was significant in the subjects analysis $\left[\mathrm{F}_{1}(1,55)=84.71\right.$; $\mathrm{p}<0.001]$ and in the items analysis $\left[\mathrm{F}_{2}(1,7)=13.30\right.$; $\mathrm{p}<0.01]$. Analysis of the 'no' responses indicated that $25 \%$ of the items with schwa deletion were processed as a nonword, and $16 \%$ of the items were 'missing'.

In a lexical decision task listeners have to make a decision about the lexical status of the item as quickly as possible. Processing of the word forms is reflected in the reaction times of the yes-responses. Contrary to the prediction, it was found that the words with epenthetic schwa, i.e. the phonological variant, were processed faster than the standard realizations. In an analysis of variance the difference was significant in the subjects analysis $\left[\mathrm{F}_{1}(1,55)=9.05 ; \mathrm{p}<0.01\right]$ and marginally significant in the items analysis $\left[\mathrm{F}_{2}(1,11)=4.62 ; \mathrm{p}=0.055\right]$. Reaction times are displayed in Figure 2. With respect to schwa deletion, the standard realizations were processed faster than the words with schwa deletion, as predicted. This difference was significant in the items analysis $\left[\mathrm{F}_{2}(1,7)=9.70\right.$; $\mathrm{p}<0.05]$, but not in the subjects analysis

Reaction times were measured from word-onset and might have been influenced by word duration. With respect to schwa deletion it was found that the standard realizations were $60 \mathrm{~ms}$ longer than the words with schwa deletion.

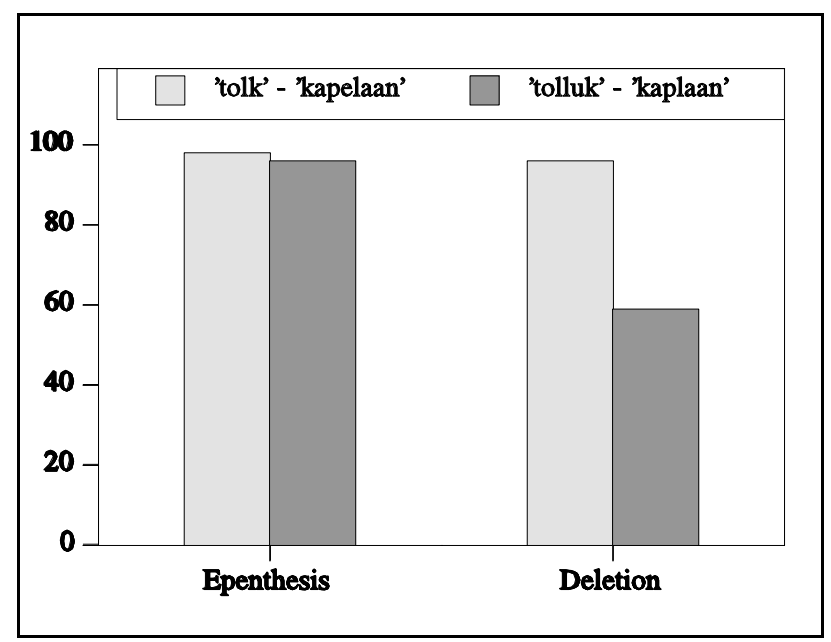

Figure 1: Hit rates (\%) for standard forms and phonological variants with schwa epenthesis and schwa deletion.
Surprisingly, words with epenthetic schwa were $60 \mathrm{~ms}$ shorter than the standard realizations, although they contain more phonetic segments. Mean durations are displayed in Table 2 .

\begin{tabular}{|l|l|l|}
\hline & Epenthesis & Deletion \\
\hline Standard & $\begin{array}{l}740 \\
\text { 'tolk' }\end{array}$ & $\begin{array}{l}834 \\
\text { 'kapelaan' }\end{array}$ \\
\hline Phonological variant & $\begin{array}{l}680 \\
\text { 'tolluk' }\end{array}$ & $\begin{array}{l}774 \\
\text { 'kaplaan' }\end{array}$ \\
\hline
\end{tabular}

Table 2: Mean durations in ms of the standard realizations and the words with schwa epenthesis and schwa deletion.

Additional analyses were carried out in which word duration was taken into consideration. First, reaction times were correlated with word durations. A relatively low correlation was found (pearson's $r=0.19$ ). Apparently, there was no systematic relation between word duration and reaction time. With respect to schwa deletion there was no significant correlation between the two measures.

Next, reaction times to both types of words ('tolk'/'kapelaan') were subjected to separate analyses of covariance. Word duration was included as the covariate. In general, the results remained the same. Again, it was found that the phonological variants with epenthetic schwa were processed significantly faster than the standard realizations $\left[\mathrm{F}_{1}(1,54)=8.21 ; \mathrm{p}<0.01\right]$. The effect disappeared in the items analysis. With respect to schwa deletion the

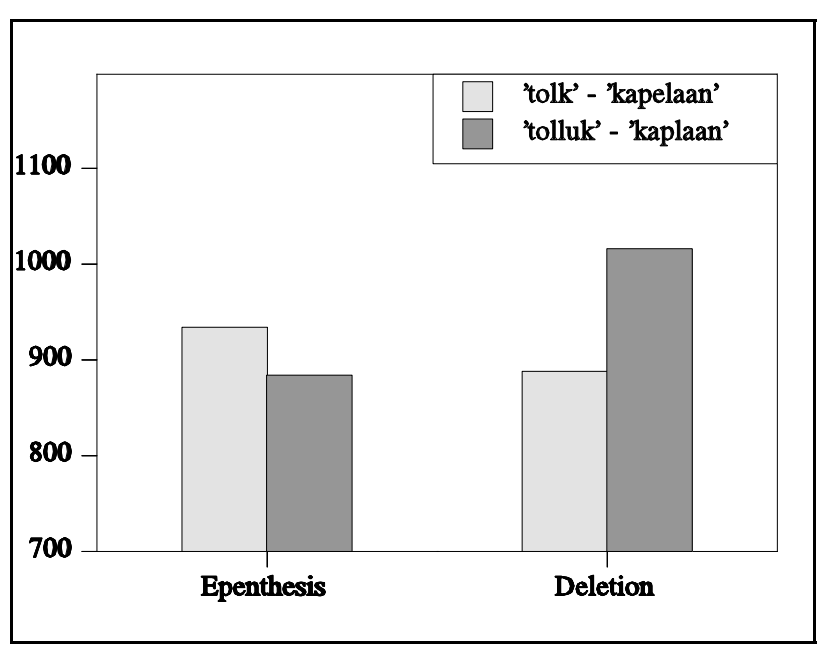

Figure 2: Reaction times (ms) for standard realizations and phonological variants with schwa epenthesis and schwa deletion. 
standard realizations were processed significantly faster than the phonological variants $\left[\mathrm{F}_{2}(1,6)=7.44 ; \mathrm{p}<0.05\right]$. No effect was found in the subjects analysis.

\section{DISCUSSION}

Two types of phonological variation were examined in relation to speech processing: schwa epenthesis and schwa deletion. Both phonological variants are optional in Dutch. It was expected that in a lexical decision experiment the standard realizations, corresponding more closely to the orthographic forms, would be responded to most rapidly and most accurately.

The results only partially confirm the predictions. With respect to schwa deletion the standard realizations displayed a much higher hit rate than the phonological variants. Words with schwa epenthesis, however, were responded to as accurately as the standard realizations. The two types of phonological variation also patterned differently in the reaction times. Words realized with schwa deletion were indeed processed less rapidly than the standard realizations, but words with schwa epenthesis were processed more rapidly than their standard counterparts. The data show that the word forms processed most accurately and most rapidly are not necessarily those that correspond to the orthographic forms.

The preference for words with epenthetic schwa (type 'tolluk') and for words without schwa deletion (type 'kapelaan') may be related to the internal structure of the words. Both types of realizations have alternating consonant-vowel sequences, whereas the standard forms without epenthesis (type 'tolk') and the phonological variants with schwa deletion (type 'kaplaan') have consonant clusters. There is reason to assume that the acoustic characteristics of consonant sequences affect the perceptibility of segments within clusters (see Treiman et al., 1982) and that speech processing is facilitated if consonant-vowel alternations occur in the word. The present data might point in that direction: Sometimes the standard realization is favoured and sometimes the phonological variant, but in each case the favoured variant avoid consonantal sequences.

The relatively low hit rate and slow responses to the words with schwa deletion may result from a change in syllabic structure. If schwa is deleted in words like 'kapelaan' a new onset cluster [pl] is created, and the syllabic structure of the word changes into a sequence of [ka] followed by [plan]. Schwa-insertion in a syllablefinal consonant cluster, however, does not lead to a change in perceived syllabic structure (van Donselaar, Kuijpers \& Cutler, 1996). The present data on schwa deletion suggest that onset clusters do not allow schwainsertion, whereas offset clusters do, and that onset clusters are perceived as integral units, whereas offset clusters are not. Treiman (1983) and Cutler, Butterfield \& Williams (1987) also provided strong evidence of the perceptual integrity of onset clusters.

\section{REFERENCES}

1. Berendsen, E. \& Zonneveld, W. "Nederlandse schwainvoeging op z'n Deens". Spektator 14: 166-169, 1985.

2. Booij, G. The phonology of Dutch. Oxford: Clarendon Press.

3. Burnage, G. CELEX: A guide for users. Centre for Lexical Information, University of Nijmegen, 1990.

4. Cutler, A., Butterfield, S. \& Williams, J. "The perceptual integrity of syllabic onsets". Journal of Memory and Language 26: 406-418, 1987.

5. Donselaar, W. van, Kuijpers, C. \& Cutler, A. "How do Dutch listeners process words with epenthetic schwa?". In Proceedings of the IVth International Congress of Spoken Language Processing, 1996.

6. Gaskell, G. \& Marslen-Wilson, W. "Phonological variation and inference in lexical access". Journal of Experimental Psychology: Human Perception and Performance 22, 144-158, 1996

7. Haas, W. de. "Partial syllabification and schwa epenthesis in Dutch". Gramma 10: 143-162, 1986.

8. Kager, R. \& Zonneveld, W. "Schwa, syllables and extrametricality". The Linguistic Review 5: 197-222, 1986.

9. Treiman, R., Salasoo, A., Slowiaczek, L. \& Pisoni, D. "Effects of syllable structure on adults' phoneme monitoring performance." Progress Report 8, Indiana University Speech Research Laboratory, 1982.

10. Treiman, R. "The structure of spoken syllables: Evidence from novel word games". Cognition 15: 49$74,1983$.

11. Trommelen, M. \& Zonneveld, W. Klemtoon en metrische fonologie. Muiderberg: Coutinho, 1989. 